\title{
Acuerdos Extrajudiciales Antimonopólicos y Principio de Eficiencia
}

\section{Resumen:}

La Ley 20.361 modificó el Decreto Ley 211 de 1973 facultando a la Fiscalía Nacional Económica para suscribir acuerdos extrajudiciales con los agentes económicos involucrados en sus investigaciones, con el objeto de cautelar la libre competencia en los mercados. Estos acuerdos extrajudiciales tienen por finalidad la eficiencia del sistema antimonopólico nacional al perseguir la desjudicialización de los procedimientos contenciosos y no contenciosos que eventualmente podrían ser conocidos por el Tribunal de Defensa de la Libre Competencia.Los mencionados acuerdos extrajudiciales exigen ciertos elementos esenciales: i) el acuerdo, que constituye la médula de la autocomposición y respecto del cual se analiza su carácter extrajudicial, preventivo, plurilateral, total, solemne y dotado de objeto y causa reales y lícitas, y ii) la actividad del Tribunal de Defensa de la Libre Competencia que, más que una forma de heterocomposición es, en estricto rigor, un acto de control y respecto del cual se estudia la iniciativa, el control y el carácter vinculante del mismo.

\section{Palabras Clave}

Acuerdo Extrajudicial Antimonopólico; Libre Competencia; Fiscalía Nacional Económica; Tribunal de Defensa de la Libre Competencia y Eficiencia.

* Abogado,

Universidad de Chile $y$ Master of Laws,

University of Chicago. Profesor Asociado de Derecho Económico y Libre Competencia, Universidad de Chile.
El presente estudio tiene por finalidad determinar el alcance y operatoria de los acuerdos extrajudiciales antimonopólicos cuya celebración por la Fiscalía Nacional Económica (FNE) ha quedado autorizada en la última reforma del Decreto Ley 211 (DL 211). Dichos acuerdos extrajudiciales deben contar con la aprobación del H. Tribunal de Defensa de la Libre Competencia (TDLC) y constituyen una importante contribución 
al principio de la eficiencia en la tutela de la libertad de competencia mercantil. Este trabajo se divide en dos secciones.

En la primera sección, denominada "Los Acuerdos Extrajudiciales de la FNE", se estudian los elementos integrantes del acuerdo extrajudicial, distinguiéndose al efecto la convención misma y la actividad de control del TDLC. Respecto de la convención se estudia la concurrencia en el Acuerdo de las siguientes notas: i) carácter extrajudicial; ii) carácter preventivo; iii) carácter plurilateral; iv) objeto real y lícito; v) carácter total; vi) causa real y lícita, y vii) carácter solemne.

En lo concerniente a la actividad del TDLC, se desarrolla, con referencia al Acuerdo, un análisis de: i) la iniciativa en el acuerdo extrajudicial; ii) el control del TDLC sobre el acuerdo extrajudicial y iii) carácter vinculante del acuerdo extrajudicial.

La segunda sección titulada "El Principio de Eficiencia como Rector de la Actividad de la FNE", da cuenta del marco normativo general que rige la FNE en relación con el principio de la eficiencia y de cómo este principio resulta aplicado en la solución de dudas y de conflictos antimonopólicos.

\section{Los Acuerdos Extrajudiciales de la FNE}

La Ley 20.361, promulgada el 13 de julio de 2009, introdujo una importantísima reforma al Decreto Ley 211 (en adelante también DL 211), en virtud de la cual creó la letra ñ) del artículo 39. A través de esta nueva letra el Legislador Antimonopólico ha facultado a la FNE para "suscribir acuerdos extrajudiciales con los agentes económicos involucrados en sus investigaciones, con el objeto de cautelar la libre competencia en los mercados" 1 .

Esta innovación corresponde a la más moderna impronta que se observa en el sistema jurídico y respecto de la cual un connotado jurista señala: "existe una fuerte tendencia doctrinaria y legislativa para incentivar la solución de conflictos a través de los equivalentes jurisdiccionales." 2

Esta fuerte tendencia ha alcanzado el orden antimonopólico infraccional a través de diversas reformas efectuadas al Decreto Ley 211 en la última década. En primer lugar, mediante la Ley 19.911 de 2003 que introdujo la institución de la conciliación antimonopólica y, más recientemente, a través de la Ley 20.361 de 2009 que consagró los acuerdos extrajudiciales de contenido judicial. Estos acuerdos extrajudiciales han de ser administrados directamente por la FNE a fin de descargar al TDLC de parte de sus múltiples tareas, aunque el Legislador Antimonopólico le reserva a este tribunal especializado un cierto ámbito de control sobre dichos acuerdos.

Artículo 39. letra ñ), inciso primero, DL 211.

Juan Colombo Campbell, "Los Actos Procesales", Tomo II, pg. 386, Editorial Jurídica de Chile, Santiago, 1997. 
La idea de encomendar a la FNE la conducción de negocios extrajudiciales - sea que consistan en equivalentes jurisdiccionales o no- y que resulten comprendidos en la letra ñ) del artículo 39 fluye claramente de la historia fidedigna de la Ley 20.361. En efecto, ésta señala que la finalidad de tales acuerdos extrajudiciales es: "desjudicializar casos de competencia"3.

Esta potestad conferida a la FNE para desjudicializar casos vinculados a la libre competencia a través de acuerdos extrajudiciales no constituye una originalidad jurídica, sino que antes bien el reconocimiento legislativo de una fórmula profusamente empleada en los Estados Unidos de América y en la Comunidad Europea.

La institución del acuerdo extrajudicial ha sido operativizada por el TDLC, puesto que recientemente ha dado aprobación a dos acuerdos extrajudiciales sometidos a la letra ñ) del artículo $39^{4}$.

\section{I.1. Elementos de los acuerdos extrajudiciales.}

Los límites bajo los cuales la FNE debe ejercitar la nueva potestad pública que le confiere la letra ñ) del artículo 39 del DL 211 resultan demarcados por este mismo precepto a través de los elementos esenciales que integran estos acuerdos extrajudiciales.

Los elementos esenciales que coexisten en este género autocompositivo son dos: i) el acuerdo, que constituye la médula de la autocomposición y ii) la actividad del TDLC, que más que una forma de heterocomposición es, en estricto rigor, un acto de control. Cabe advertir que, para efectos de este análisis, empleamos los términos composición, autocomposición y heterocomposición en un sentido lato, esto es, comprensivo tanto de una solución de conflictos (contencioso sancionatorio) como de una solución de dudas antimonopólicas (no contencioso consultivo).

\section{I.1. Acuerdo Extrajudicial}

\section{i) Carácter Extrajudicial del Acuerdo}

Los acuerdos a que se refiere la letra ñ) del artículo 39 no son sino convenciones creadoras, modificatorias o extintivas de derechos y obligaciones.

Estos acuerdos son extrajudiciales en el sentido que se negocian y celebran fuera de sede judicial, sin perjuicio de que posteriormente deban ser conocidos y aprobados por el TDLC para surtir eficacia antimonopólica. El carácter extrajudicial de estas

3 Historia de la Ley 20.361, Informe Comisión de Constitución, pg. 152, Biblioteca del Congreso Nacional de Chile, 13 de julio de 2009.

4 Véase causas Rol AE Nº1-10 y Rol AE Nº2-10 tramitadas ante el TDLC. 
convenciones implica que las mismas sean celebradas tanto al margen de un procedimiento contencioso como de uno no contencioso susceptible de ser ventilado ante el TDLC, puesto que como bien ha señalado un gran jurista nacional no cabe identificar lo judicial con lo jurisdiccional ${ }^{5}$. De esta forma, el carácter extrajudicial implica que estos acuerdos no solo se celebren fuera de un procedimiento jurisdiccional sino que también al margen de un procedimiento voluntario o no contencioso ${ }^{6}$.

Surge la pregunta de por qué estas convenciones reciben el calificativo de "acuerdos". Parecería que éste deriva de la singularidad de sus contenidos, que están siempre referidos a materias judiciales. Este aserto se prueba por las siguientes razones:

a. Se celebran entre la FNE y uno o más agentes económicos involucrados en una investigación. Las investigaciones de la FNE pueden acabar en la interposición de una consulta o de un requerimiento ante el TDLC. Cabe recordar que, luego de la reforma efectuada por la Ley 20.361 al DL 211, la FNE puede consultar, de propia iniciativa, al TDLC acerca de un hecho, acto o convención a ejecutarse por un(os) tercero(s). Luego, resulta lógico concluir que quien se halla involucrado en una investigación y llega a un acuerdo extrajudicial con la FNE es porque prefiere anticiparse a las resultas de una eventual consulta o de un eventual requerimiento ante el TDLC, y

b. Así lo consigna la historia fidedigna de la Ley 20.361 al referirse a la letra ñ) del artículo 39 y establecer que la finalidad de estas convenciones es: "desjudicializar casos de competencia, es decir, permitir llegar a acuerdos extrajudiciales en términos similares a las soluciones alternativas a que puede llegar el Ministerio Público, contando siempre con la autorización del tribunal' ". Luego, se trata de casos que hubieran podido acabar siendo conocidos por el TDLC y que, en virtud de estas convenciones, no llegan a ser objeto de la actividad que este tribunal especializado podría desplegar a través de un procedimiento consultivo o de un proceso contencioso.

Atendido el contenido judicial que caracteriza los acuerdos en comento, éstos suelen recibir la denominación de "negocios jurídicos extraprocesales con contenido procesal" y

Francisco Hoyos Henrechson, "Temas Fundamentales de Derecho Procesal”, pg. 25, Editorial Jurídica de Chile, Santiago, 1987. Seńala este autor: "(...) la doctrina organicista de la jurisdicción, expuesta principalmente por Carré de Malberg, se funda en la premisa de que serían jurisdiccionales todos los actos emanados del Poder Judicial (rectius, de sus órganos, esto es, de los tribunales de justicia). Esta tesis debe ser desechada de plano, ya que la sola consideración de las diversas facultades que a los órganos jurisdiccionales (tribunales de justicia) se atribuyen, v. gr., en nuestro propio ordenamiento jurídico (C.O.T, arts. $1^{\circ}, 2^{\circ}$ y $3^{\circ}$ ), especialmente en el Libro IV del CPC, así como en numerosas otras disposiciones dispersas en distintos cuerpos de leyes, bastaría para percatarse de que no toda la actividad de los tribunales de justicia, expresada en la posibilidad de realizar actos de la más variada índole, es jurisdiccional (...)".

6 Entre los acuerdos judiciales cabe mencionar la conciliación antimonopólica (regulada expresamente por el artículo 22 del DL 211) y el desistimiento que, generalmente, ha sido rechazado por la jurisprudencia del TDLC. A modo de ejemplo de esta última situación, véase resolución intermedia de 13 de diciembre de 2007 en Rol C 86-2006.

Historia de la Ley 20.361, Informe Comisión de Constitución, pg. 152, Biblioteca del Congreso Nacional de Chile, 13 de julio de 2009. 
se distinguen ya que por su "caracteristico contenido influyen de modo decisivo sobre el desenvolvimiento del proceso, una vez que sea instaurado; no son, sin embargo, manifestaciones de voluntad, unilaterales o bilaterales, emitidas dentro del proceso pendiente, $n i$ tienen por tanto el carácter de actos procesales. El momento de la declaración de voluntad ocurre ordinariamente antes de la constitución de la relación jurídica procesal, es decir, cuando no se podría hablar ni de partes en el proceso, que no está constituido todavía, ni de actos procesales" ${ }^{\prime}$. Lo que señala respecto del proceso es también predicable del procedimiento consultivo, según explicaremos.

\section{ii) Carácter Preventivo del Acuerdo Extrajudicial}

El acuerdo extrajudicial de que da cuenta la letra ñ) del artículo 39 del Decreto Ley 211 tiene por objeto prevenir una consulta o un litigio antimonopólico; de allí su carácter precautorio. Ello se desprende de la circunstancia de que el acuerdo extrajudicial se vincula, ya sea en forma causal o bien ocasional, a una investigación desarrollada por la FNE? . La investigación de la FNE debe hallarse en curso, puesto que el acuerdo ha de celebrarse con uno o más agentes económicos involucrados en la investigación. Si la investigación se halla en curso es porque aún no se ha dado inicio a un procedimiento consultivo o contencioso ante el TDLC. Así lo reconoce la jurisprudencia existente en la materia ${ }^{10}$.

Un acuerdo extrajudicial tendría este carácter preventivo toda vez que podría contemplar un pactum de non petendo clásico (relativo a la acción de demanda antimonopólica) o uno moderno (relativo a la petición de consulta antimonopólica) ${ }^{11}$. En otras palabras, nada impide que entre los posibles acuerdos extrajudiciales se halle un pactum de non petendo relativo al derecho de consulta que asiste a la FNE luego de la reforma efectuada por la Ley 20.361 al DL 211. En efecto, luego de dicha enmienda el artículo $18 \mathrm{~N}^{\circ} 2$ del DL 211 preceptúa: "Conocer a solicitud de quien tenga interés legítimo, o del Fiscal Nacional Económico, los asuntos de carácter no contencioso que pueden infringir las disposiciones de la presente ley, sobre hechos, actos o contratos existentes o por celebrarse (...)" (énfasis agregado). Luego, el Legislador Antimonopólico ha conferido expresamente a la FNE la potestad pública para efectuar consultas, zanjando así definitivamente la controversia preexistente a la mentada reforma en cuanto a si podía o no la FNE iniciar tales procedimientos no contenciosos.

\footnotetext{
Ugo Rocco, "Derecho Procesal Civil”, Sección 1.7.1.4.1, pg. 354, Editorial Jurídica Universitaria, México, 2002.

Artículo 39, letra ñ), inciso primero, DL 211.

Véase causas Rol AE N01-10 y Rol AE N02-10 tramitadas ante el TDLC.

11 Los pactum de non petendo presentan, en el ámbito de la libre competencia, una doble modalidad: la clásica, según la cual la FNE acordaría no ejercer el derecho de acción antimonopólica y otra, de más reciente cuño, según la cual la FNE asumiría el compromiso de no ejercer el derecho de consulta antimonopólica.
} 


\section{iii) Carácter Plurilateral del Acuerdo Extrajudicial}

Estos acuerdos tienen por partes necesariamente a la FNE y a uno o más agentes económicos involucrados en las investigaciones que dicha autoridad pública realiza. De allí que aquéllos puedan ser caracterizados como plurilaterales.

Los agentes económicos no necesariamente corresponden a personas privadas, sino que también puede tratarse de autoridades públicas, empresas públicas del Estado, sociedades estatales, autoridades privadas y simples particulares. Asimismo, puede acontecer que los agentes económicos involucrados sean pluralidad y, además, exhiban diversa naturaleza entre sí, v.gr., una discriminación arbitraria monopólica perpetrada por un particular con la colaboración de una autoridad pública administrativa.

Es importante destacar la fórmula empleada por el precepto en análisis: éste no alude a agentes económicos "investigados" sino que más precisamente a "involucrados en sus investigaciones" y cabe estar involucrado en una investigación bajo diversas formas. Así, la primera y principal forma de estar involucrado en una investigación es como "investigado o afectado", pero también se puede estar envuelto en aquélla como denunciante, informante, declarante o aportante de antecedentes, testimonios u otros medios probatorios relativos a las conductas investigadas.

\section{iv) Objeto Real y Lícito del Acuerdo Extrajudicial}

Procede destacar que estos acuerdos extrajudiciales no presentan uno o más objetos específicos, puesto que el Legislador de la Libre Competencia ha conferido a la FNE amplia discrecionalidad administrativa para determinar el contenido y alcance de estas convenciones. En efecto, la FNE se encuentra revestida de claras atribuciones para determinar el contenido de estos acuerdos extrajudiciales, puesto que según dispone el Decreto Ley 211: "Podrá [la FNE], en consecuencia defender los intereses que le están encomendados en la forma que estime arreglada a derecho, según sus propias apreciaciones"12. No cabe duda que un acuerdo extrajudicial, en cuanto institución, está arreglado a derecho, toda vez que tal forma compositiva se halla expresamente tratada por el artículo 39, letra ñ), del mencionado cuerpo normativo. La intervención de la FNE es de la esencia del acuerdo extrajudicial, puesto que al actuar aquélla en calidad de parte desempeña una doble función:

i. la FNE podría ser consultante o requirente y dar inicio por estas vías a un procedimiento antimonopólico ante el TDLC. La FNE, por tanto, tiene poder de acción y de petición; consecuencialmente, se halla investida de legitimidad para celebrar un acuerdo extrajudicial que se refiera a tales potestades públicas. La FNE da cumplimiento así al mandato legislativo de agilizar la solución de los conflictos de libre competencia, por una parte, y por otra, de evitar una sobrecarga 
de causas en el TDLC con los consiguientes costos sociales que ello irrogaría a la economía nacional, y

ii. al intervenir en un acuerdo extrajudicial la FNE continúa representando el interés de la sociedad toda en la tutela de la libre competencia, de la misma forma como lo habría podido hacer al presentar una consulta o un requerimiento ${ }^{13} \mathrm{y}$, por tanto, en dicha intervención implícitamente se pronuncia acerca de esa convención en su relación con la libre competencia.

El DL 211 ciñe los objetos de estos acuerdos extrajudiciales a una doble exigencia: i) que versen sobre materias judiciales, entendidas éstas en su amplia acepción de actividad procedimental del TDLC; y ii) que contribuyan a "cautelar la libre competencia en los mercados". Ésta es la finalidad para la cual existe la FNE y que, por tanto, ha de guiar toda la actividad de esta autoridad pública administrativa.

Podría alguien plantear la idea de que existe una tercera exigencia aplicable al objeto de estos acuerdos extrajudiciales y que ésta hallaría fundamento en la historia fidedigna, cuyo pasaje pertinente señala que la letra ñ) del artículo 39 busca: "permitir llegar a acuerdos extrajudiciales en términos similares a las soluciones alternativas a que puede llegar el Ministerio Público"14. La similitud a que alude la historia fidedigna es meramente referencial y carece del sentido operativo necesario para llegar a constituir una exigencia sobre el objeto de estos acuerdos extrajudiciales. En efecto, todas las salidas alternativas contempladas en el proceso penal suponen siempre la existencia de un imputado formalizado por el Ministerio Público y, por ende, la participación activa del órgano jurisdiccional competente, lo que no resulta conciliable con los términos de la letra ñ) del artículo 39 del DL 211.

La variedad de acuerdos, referidos a materias judiciales, que la FNE puede utilizar para cautelar la libre competencia genera una vasta gama de objetos específicos alternativos, que no se agota en los denominados equivalentes jurisdiccionales. La doctrina nacional ha indicado como negocios extrajudiciales de contenido procesal los siguientes equivalentes jurisdiccionales: la transacción, el avenimiento ${ }^{15}$ y la renuncia ${ }^{16}$. Los acuerdos comprendidos en la letra ñ) del artículo 39 del DL 211 exceden los equivalentes jurisdiccionales indicados. Dicho aserto se fundamenta en lo siguiente:

a. la mentada letra ñ) contempla acuerdos extrajudiciales y lo extrajudicial se contrapone a toda actividad judicial, tanto en su forma contenciosa como no contenciosa. De allí que estos acuerdos pueden ser equivalentes a una decisión jurisdiccional del TDLC como a una decisión no contenciosa del TDLC

Decreto Ley 211, artículos 39, letras b) y c), y artículo $18 \mathrm{~N}^{\circ} 1$ y 2.

14 Historia de la Ley 20.361, Informe Comisión de Constitución, pg. 152, Biblioteca del Congreso Nacional de Chile, 13 de julio de 2009.

15 Cabe advertir que avenimiento no es sinónimo de conciliación, puesto que esta última necesariamente se realiza en un proceso antimonopólico. Artículo 22, inciso primero, DL 211.

16 Juan Colombo Campbell, "Los Actos Procesales", Tomo II, pg. 382, Editorial Jurídica de Chile, Santiago, 1997. 
b. la historia fidedigna de esta letra ñ) nos señala que la finalidad de estas convenciones es: "desjudicializar casos de competencia", descripción ésta que muestra una notable precisión. En efecto, no se aludió a desjudicializar conflictos o litigios antimonopólicos sino que casos de competencia, lo cual denota una manifiesta intención de comprender no solo demandas sino que también consultas antimonopólicas; y

c. nada se señala en la letra ñ) del artículo 39 del DL 211 en orden a exceptuar casos de competencia de naturaleza no contenciosa o consultiva; más aún, si así se interpretase ello resultaría contradictorio con la finalidad de descargar al TDLC de parte de los múltiples procedimientos que se ventilan ante este tribunal especializado.

Con todo, corresponde advertir que la misma naturaleza de la libre competencia y la estructura de la jurisdicción antimonopólica excluyen la aplicación de ciertos negocios extrajudiciales de contenido procesal, como acontece con el compromiso ${ }^{17}$, que deroga la jurisdicción de los órganos ordinarios llamados a resolver (en la especie el TDLC) o con el pactum de foro prorrogando, que regula convencionalmente la actividad de los órganos jurisdiccionales en relación con la competencia territorial. Por contraste, otros negocios extrajudiciales resultan aceptados en el orden antimonopólico, tales como las transacciones y los pactum de non petendo.

Atendida la flexibilidad de que dispone la FNE para determinar los objetos de los acuerdos extrajudiciales en comento, es factible concebir combinaciones de las convenciones anteriores, en tanto se respeten los límites genéricos expuestos. Así, a modo de ejemplo, podría celebrarse un acuerdo extrajudicial que combinara un pactum de non petendo clásico con uno moderno. En este sentido, cabe recordar la jurisprudencia nacional ${ }^{18}$ y también la colombiana ${ }^{19}$, que manifiestan que es posible componer un acuerdo extrajudicial -específicamente una transacción- sobre la base de una pluralidad de formas contractuales en tanto y en cuanto se dé cumplimiento a los requisitos de cada una de ellas.

17 El compromiso ha sido conceptualizado jurisprudencialmente como un contrato autónomo e independiente en que las partes acuerdan sustraer determinadas materias del conocimiento de la jurisdicción ordinaria para someterlas a un tribunal arbitral. Si se han designado árbitros será compromiso y si falta su nominación, cláusula compromisoria (Fallo de 28 de mayo de 1980, Rev. T. 77, 2a parte, sec. $2^{\text {a }}$, pg. 64).

18 La circunstancia de que la transacción sea un contrato propio y que, en determinadas hipótesis, deba someterse a formalidades características, no significa que, llenadas éstas, se entienden cumplidas las inherentes a los demás contratos que por accidente se le incorporan. Porque si ello se aceptara de un modo absoluto, resultaría que sería lícito prescindir de todas las garantías o formalidades exigidas por la ley para la validez de estos últimos contratos por el solo hecho de introducir un determinado contrato en otro que las partes hicieran figurar como principal. Excma Corte Suprema, 29 de mayo de 1911. R., t.9, secc.1 a, p.139.

19 Jorge Ortega Torres, "Código Civil con Notas, Concordancias, Jurisprudencia de la Corte Suprema y Normas Legales Complementarias”, pg. 1084, Bogotá, 1977. La jurisprudencia colombiana manifiesta que es posible combinar una transacción con otras figuras para facilitar sus resultados dirimentes. Así, el acuerdo extrajudicial adquiere una naturaleza mixta, pero la transacción no se desnaturaliza por ello, debiendo aplicarse a cada una de las figuras integradas en torno a aquélla sus respectivas exigencias normativas y hasta donde lo permita la intención de las partes, cuyo motivo determinante es el propósito de transigir. 


\section{v) Carácter Total del Acuerdo Extrajudicial}

A nuestro juicio, a través de un acuerdo, podría lograrse la terminación total de las investigaciones conducidas por la FNE contra las personas involucradas en una investigación. En consecuencia, una vez que un acuerdo fuese aprobado por el TDLC, las personas involucradas en una investigación perderían dicha calidad en la misma.

\section{vi) Causa del Acuerdo Extrajudicial}

La causa del Acuerdo es real y lícita, puesto que no es otra que el interés de todas las partes que intervienen en el respectivo acuerdo extrajudicial de poner término a una investigación que les vincula precaviendo, entre otras consecuencias, una eventual consulta antimonopólica o un posible requerimiento antimonopólico.

\section{vii) Carácter Solemne del Acuerdo Extrajudicial}

La solemnidad consiste en que un acuerdo extrajudicial en el orden de la libre competencia ha de ser formulado en un acta o documento escrito, puesto que solo de esta forma podrá el TDLC ejercer la actividad de conocimiento y aprobación prevista en el Decreto Ley 211. Así, constituyen formalidades ad solemnitatem la escrituración de la convención respectiva y la resolución aprobatoria de ésta emitida por el TDLC.

\section{I.2. Actividad del TDLC en Relación con el Acuerdo Extrajudicial}

Una vez que un acuerdo sea suscrito por la FNE y una o más personas involucradas en una investigación, aquél deberá ser aprobado o rechazado por el TDLC, el cual ha de ceñirse al procedimiento previsto en el artículo 39, letra ñ), inciso segundo, del Decreto Ley $211^{20}$. A continuación, analizamos la actividad del TDLC en el acuerdo extrajudicial.

\section{i. Iniciativa del Acuerdo Extrajudicial}

El TDLC carece de toda iniciativa en un acuerdo extrajudicial; de allí que éste necesariamente se origina en las partes que lo suscriben. Esta situación deriva de la reforma introducida por la Ley 19.911 al Decreto Ley 211, según la cual el TDLC quedó privado de atribuciones para iniciar procedimientos de oficio, lo cual con mayor ra-

20 "Serán atribuciones y deberes del Fiscal Nacional Económico: ñ) Suscribir acuerdos extrajudiciales con los agentes económicos involucrados en sus investigaciones, con el objeto de cautelar la libre competencia en los mercados. El Tribunal tomará conocimiento del acuerdo en una sola audiencia, sin forma de juicio, convocada especialmente al efecto, dentro del quinto día hábil de recibidos los antecedentes, durante la cual podrá escuchar alegatos de las partes comparecientes al acuerdo. El Tribunal deberá aprobar o rechazar el acuerdo en un plazo máximo de quince días hábiles, contados desde la fecha de la audiencia. Estas resoluciones una vez ejecutoriadas serán vinculantes para las partes que comparecieron al acuerdo y en su contra sólo procederá el recurso de reposición.” 
zón se predica de los acuerdos extrajudiciales. Entre los procedimientos indicados se cuentan no solo los contenciosos sino que también los no contenciosos o malamente denominados de jurisdicción voluntaria. A esta última categoría pertenece la actividad de control sobre acuerdos extrajudiciales.

\section{ii. Control del TDLC sobre el Acuerdo Extrajudicial}

El TDLC examina un acuerdo a fin de verificar si lo señalado en éste contribuye a la tutela de la libre competencia y así dictar una resolución aprobatoria o denegatoria del acuerdo. De prosperar este procedimiento, el TDLC aprobaría un acuerdo, con lo cual necesariamente la FNE debería finalizar una investigación. Este control se funda en la circunstancia de que la libre competencia es una materia de orden público ${ }^{21}$. Esta intervención del TDLC no desvirtúa en forma alguna el carácter convencional de un acuerdo, puesto que ciertos acuerdos extrajudiciales, tales como algunas transacciones regidas por el Código Civil, también requieren aprobación judicial para su validez ${ }^{22}$.

La actividad contralora que realiza el TDLC respecto del acuerdo extrajudicial no pertenece al orden jurisdiccional (aunque sí al judicial), puesto que si se tratase de ejercicio de jurisdicción dicho acuerdo jamás podría ser caracterizado como equivalente jurisdiccional ${ }^{23}$. Así, la naturaleza de esta actividad contralora es de orden no contencioso. La actividad de control que ha de efectuar el TDLC reviste un carácter específico y concreto y resulta necesaria para que un acuerdo extrajudicial surta toda su eficacia y, por ello, debemos calificar este acuerdo extrajudicial como solemne.

El TDLC debe conocer el acuerdo extrajudicial en una audiencia única, sin forma de juicio y especialmente convocada al efecto, dentro del quinto día hábil de recibidos los antecedentes pertinentes. El TDLC tiene la facultad de, en dicha audiencia, escuchar los alegatos de las partes concurrentes al acuerdo. En un plazo máximo de quince días hábiles contados desde la referida audiencia, el TDLC deberá aprobar o rechazar el respectivo acuerdo.

Dicha actividad de control supone que el TDLC, en el evento de rechazar un acuerdo extrajudicial, deberá indicar expresamente cuáles son los aspectos del mismo que motivan el rechazo. En consecuencia, las partes suscriptoras de aquél podrán rectificar los aspectos objetados por el TDLC y someter el acuerdo extrajudicial rectificado al conocimiento y aprobación delTDLC. En el evento que las partes no estén dispuestas a ello, el procedimiento investigativo podría continuar adelante. A nuestro juicio, el

21 Enrique Navarro Beltrán, "Orden Público Económico y Libre Competencia”, en Revista de Derecho de la Universidad Finis Terrae, Año VII Nº, Santiago, 2003.

22 Código Civil, artículo 2451: "La transacción sobre alimentos futuros de las personas a quienes se deban por ley, no valdrá sin aprobación judicial; ni podrá el juez aprobarla, si en ella se contraviene a lo dispuesto en los artículos 334 y 335." (énfasis agregado).

23 Confrontar, Francisco Hoyos Henrechson, "Temas Fundamentales de Derecho Procesal”, Capítulo VII, pg. 69, Editorial Jurídica de Chile, 1987. Este autor destaca que lo que caracteriza un equivalente jurisdiccional es que permite poner término a un litigio fuera de sede jurisdiccional. No obstante lo anterior, el acuerdo extrajudicial culmina su desarrollo en sede judicial, según hemos explicado. 
rechazo de un acuerdo extrajudicial por parte del TDLC en forma alguna precluye la interposición de una posterior consulta antimonopólica por las mismas partes suscriptoras del acuerdo repudiado y aunque aquél verse sobre la misma operación que se ha pretendido resolver a través de la letra ñ) del artículo 39 del DL 211. Estimamos que no existe tal preclusión precisamente por la circunstancia de que las potestades públicas a ser ejercitadas por el TDLC tienen objetos formales muy diversos: en el caso del acuerdo extrajudicial corresponde al TDLC determinar si el contenido de éste cautela adecuadamente la libre competencia, en tanto que en el caso de una consulta antimonopólica la finalidad es establecer si un determinado hecho, acto o convención es contradictorio con la libre competencia.

Cabe observar que el TDLC carece de atribuciones para modificar un acuerdo extrajudicial que se le presenta a su examen, puesto que el artículo 39, letra ñ), inciso segundo, del Decreto Ley 211 sólo le permite realizar el control descrito por dicha disposición, esto es, aprobar o rechazar ${ }^{24}$. Nada de lo indicado impide en forma alguna que el TDLC solicite y reitere a las partes, tantas veces como sea necesario, todos los antecedentes e informaciones que resulte razonable para realizar esta actividad de control ${ }^{25}$.

iii. Carácter Vinculante del Acuerdo Extrajudicial

El DL 211 expresa: "Estas resoluciones una vez ejecutoriadas serán vinculantes para las partes que comparecieron al acuerdo". En efecto, no solo el acuerdo extrajudicial es vinculante para las partes sino que la resolución aprobatoria también lo es; luego, la FNE no puede consultar ante el TDLC el asunto ya resuelto, máxime si ello así ha sido pactado en el acuerdo. Cabe advertir que el efecto vinculante queda acotado estrictamente a los asuntos objeto del acuerdo y, por tanto, no puede extenderse a otras materias. Con todo, la ventaja del acuerdo extrajudicial debidamente aprobado por el TDLC por sobre una resolución o una sentencia dictada por el TDLC con motivo de una consulta o una demanda antimonopólicas, según corresponda, radica en que dicho acuerdo extrajudicial puede involucrar e incluir aspectos que no han sido objeto de consulta o requerimiento. En efecto, en una resolución o en una sentencia el TDLC está limitado por su competencia específica y, por tanto, en riesgo de ultra petita o extra petita en caso de excederse de aquélla. Así, otra de las importantes ventajas del acuerdo extrajudicial por sobre la actividad consultiva o sentenciadora del TDLC deriva de la circunstancia de que aquél es plurilateral y se halla definido por las partes intervinientes, en tanto que en las resoluciones y sentencias las soluciones son determinadas unilateralmente por el TDLC.

iv. A modo de síntesis, podemos afirmar que el acuerdo extrajudicial tratado por el artículo 39, letra ñ), del DL 211, ha de ser calificado como una convención pre-

24 Esto es perfectamente consistente con la jurisprudencia nacional que ha seńalado que el juez que interviene en una transacción -especie de acuerdo extrajudicial- sólo tiene competencia para aprobarla o rechazarla. Excma Corte Suprema, 29 de mayo 1911. R., t.9, secc. 1a, pg. 139.

25 A modo de ejemplo, véase Acuerdo Extrajudicial entre FNE y SMU S.A. en Rol AE No02-10 y resolución intermedia del TDLC de 8 de julio de 2010. 
procedimental y pre-procesal, de origen extrajudicial (aunque requiera aprobación del TDLC) y de naturaleza voluntaria.

\section{El Principio de Eficiencia como Rector de la Actividad de la FNE}

\section{II.1. Marco Normativo General}

La Administración del Estado debe ceñirse a los principios de la eficiencia y de la eficacia por mandato expreso de la Ley General de Bases de Administración del Esta$\mathrm{do}^{26}$. Aunque la FNE no aparezca expresamente mencionada en el artículo $1^{\circ}$, inciso segundo, de la referida Ley de Bases, aquélla ciertamente pertenece a la Administración del Estado atendida su calidad de servicio público descentralizado, sometido a la supervigilancia del Presidente de la República a través del Ministerio de Economía, Fomento y Turismo ${ }^{27}$. En consecuencia, las autoridades públicas indicadas en el artículo $1^{\circ}$, inciso segundo, de la mencionada Ley de Bases no son las únicas integrantes de la Administración del Estado, puesto que aquel precepto no constituye ni pretende constituir un catálogo exhaustivo de tales integrantes ${ }^{28}$.

Así, la FNE y, particularmente el Fiscal Nacional Económico en cuanto jefe de este servicio público, deben velar por una eficiente e idónea administración de los medios públicos de que dicho ente público se halla dotado y por el debido cumplimiento de la función pública que el DL 211 le ha asignado ${ }^{29}$. Una dimensión - aunque ciertamente no la única - de una eficiente administración de los medios públicos radica en evitar la duplicación o interferencia de funciones ${ }^{30}$, lo que en la especie se traduce en que la FNE no debe trasladar al TDLC aquellos cometidos que la FNE puede realizar por sí misma en forma expedita y con menor insumo de recursos que el Tribunal Antimonopólico. Asimismo, la FNE al intentar solucionar un conflicto antimonopólico deberá procurar la rapidez y simplificación de los trámites ${ }^{31}$, esto es, deberá optar por aquellas fórmulas más ágiles y directas en la solución de aquél. En tal sentido, la FNE ha de limitar las

26 Artículo 3, inciso segundo, de la Ley 18.575 Orgánica Constitucional de Bases Generales de la Administración del Estado.

27 Artículo 33, inciso primero, DL 211.

28 En este sentido, Domingo Valdés Prieto, "Libre Competencia y Monopolio", pg. 226, nota 212, Editorial Jurídica de Chile, Santiago, 2006. Otra prueba de la falta de exhaustividad de la nómina de autoridades públicas que integran la Administración del Estado de conformidad a la Ley de Bases lo constituye la circunstancia de que con anterioridad a la reforma introducida al DL 211 por la Ley 19.911 nunca se mencionó a las Comisiones Preventivas Central y Regionales que eran organismos antimonopólicos de naturaleza administrativa.

29 Artículo 5, inciso primero, de la Ley 18.575 Orgánica Constitucional de Bases Generales de la Administración del Estado.

30 Artículo 5, inciso segundo, de la Ley 18.575 Orgánica Constitucional de Bases Generales de la Administración del Estado.

31 Artículo 8, inciso primero, de la Ley 18.575 Orgánica Constitucional de Bases Generales de la Administración del Estado. 
formalidades de sus procedimientos a aquéllas que establezcan las leyes y reglamentos, evitando fórmulas o alternativas que resulten más engorrosas o lentas ${ }^{32}$.

Toda investigación constituye un procedimiento administrativo cuyo objeto es indagar acerca de hechos, actos o convenciones ${ }^{33}$ con la finalidad de comprobar infracciones ${ }^{34}$ al DL 211. Las investigaciones pueden instruirse de oficio o en virtud de denuncias y exhibir el carácter de públicas o reservadas. Este procedimiento administrativo investigativo resulta alcanzado por la Ley 19.980 que Establece Bases de los Procedimientos Administrativos que Rigen los Actos de los Órganos de la Administración del Estado. En efecto, atendido que la FNE constituye un servicio público ${ }^{35}$ resulta claro que se le aplica la mentada Ley de Bases de los Procedimientos Administrativos ${ }^{36}$ en aquello que no resulte incompatible con la naturaleza del procedimiento administrativo de naturaleza investigativa que nos ocupa ${ }^{37}$. Dispone al efecto la Ley de Bases: "Principio de Economía Procedimental. La Administración debe responder a la máxima economía de medios con eficacia, evitando trámites dilatorios" 38 .

Los principios de la eficiencia y de la eficacia que alcanzan a la FNE y al Fiscal Nacional Económico deben ser cuidadosamente observados, puesto que su transgresión constituye una contravención al principio de la probidad administrativa ${ }^{39}$.

\section{II.2. El Principio de la Eficiencia en la Solución de Dudas y Conflictos Antimonopólicos}

Habida consideración de que todo procedimiento judicial conlleva ciertas desventajas, tales como la duración del mismo, el empleo de importantes energías necesarias para su avance y desenvolvimiento, así como las dificultades propias de un estadio probatorio adecuado, han emergido los acuerdos extrajudiciales como formas preventivas de consultas y requerimientos mediante los cuales se reducen tales costos a través de una convención aprobada por el TDLC.

La moderna tendencia observada no solo en Chile sino que también en el caso de Estados Unidos de América y la Comunidad Europea es generar alternativas de prevención de consultas y de conflictos antimonopólicos por vías extrajudiciales y, en lo posible,

32 Artículo 8, inciso segundo, de la Ley 18.575 Orgánica Constitucional de Bases Generales de la Administración del Estado.

33 Artículo 39, letra j), DL 211.

34 Artículo 39, letra a), inciso primero, DL 211.

Artículo 33, inciso primero, DL 211.

Artículo 2, Ley 19.980 que Establece Bases de los Procedimientos Administrativos que Rigen los Actos de los Órganos de la Administración del Estado.

37 Artículo 1, inciso primero, Ley 19.980 que Establece Bases de los Procedimientos Administrativos que Rigen los Actos de los Órganos de la Administración del Estado: "En caso que la ley establezca procedimientos administrativos especiales, la presente ley se aplicará con carácter de supletoria”.

38 Artículo 9, inciso primero, Ley 19.980 que Establece Bases de los Procedimientos Administrativos que Rigen los Actos de los Órganos de la Administración del Estado.

39 Artículo $62 \mathrm{~N}^{\circ} 8$ de la Ley 18.575 Orgánico Constitucional de Bases Generales de la Administración del Estado. 
cuando éstos se encuentran todavía en estadios pre-procesales. Esta tendencia es la que se conoce como desjudicialización de consultas y demandas de libre competencia, trasladándose así la solución de las mismas desde fórmulas heterocompositivas hacia alternativas de naturaleza autocompositiva.

En el caso chileno, esta búsqueda de la desjudicialización de los casos de competencia no solo tiene por objeto reducir la carga del TDLC, sino que adicionalmente conferir a la FNE nuevas potestades para aumentar "la rapidez de la intervención del sistema de defensa de la competencia” ${ }^{30}$. En otras palabras, el Legislador Antimonopólico ordena que la FNE sea proactiva en el empleo de sus nuevas potestades públicas a fin de coadyuvar a las tareas del TDLC en el ámbito de sus respectivas competencias, pero también con el objeto de evitar los costos y dilaciones que entrañaría trasladar todas las dudas y conflictos antimonopólicos a un procedimiento que habría de ventilarse ante el TDLC.

En Estados Unidos de América la referida desjudicialización constituye una fórmula profusamente empleada. Así, en dicho país, al menos el 80\% de los casos en los cuales intervienen las autoridades públicas gubernamentales que tutelan la libre competencia nunca son llevados a juicio, sino que aquéllos son resueltos a través de alguna forma de acuerdo voluntario ${ }^{41}$.

En el caso de la Comunidad Europea se emitió la Regulación 1/2003, en cuyo considerando $13^{\circ}$ se establece que en el curso de la investigaciones que pueden conducir a la prohibición de un acuerdo o de una práctica, la empresa puede ofrecer a la Comisión Europea la asunción de compromisos que satisfagan sus observaciones antimonopólicas expresadas en una evaluación preliminar o prima facie. La Comisión puede aceptar tales compromisos y conferirles el carácter de vinculantes en la medida que éstos sean necesarios y proporcionados a las mencionadas observaciones antimonopólicas y sin concluir si en los hechos se ha producido o no una infracción monopólica, a la par que aquélla declara que ya no hay fundamento para una acción antimonopólica. Esta atribución de la Comisión Europea permite alcanzar acuerdos (settlements) con agentes económicos investigados, todo ello en el curso de sus investigaciones y previo a la emisión de órdenes de cese y desistimiento vinculadas con aquéllos. Estos acuerdos le permiten a la Comunidad Europea suspender o terminar su investigación en virtud de que aquéllos permiten ajustar las conductas objetadas a la normativa de la Comunidad Europea ${ }^{42}$.

Lo expuesto conduce a concluir que existe una prelación natural, fundada en el principio de la eficiencia que rige la actividad de la FNE, para la prevención de dudas y

40 Historia de la Ley 20.361, Primer Informe Comisión de Economía, pg. 240, Biblioteca del Congreso Nacional de Chile, 13 de julio de 2009.

${ }^{41}$ Milton Handler, Harlan M. Blake, Robert Pitofsky y Harvey J. Goldschmid, "Cases and Materials on Trade Regulation”, pg. 117, The Foundation Press, Inc., $3^{\text {rd }}$ edition, New York, 1990.

42 Article 9 of Regulation 1/2003, Council Regulation (EC) $N^{\circ} 1 / 2003$ of December 16, 2002, on the Implementation of the Rules on Competition laid down in Articles 81 and 82 of the Treaty, O.J. 2003, L 1/1. Einer Elhauge and Damien Geradin, "Global Antitrust Law and Economics", pg. 47, Foundation Press, New York, 2007. 
conflictos antimonopólicos en los cuales interviene dicho ente público administrativo. Esta prelación comienza con las fórmulas menos onerosas para acabar con las más costosas. Cabe advertir que, de conformidad con el marco normativo general que rige a la FNE y que fuera antes expuesto, esta autoridad pública no puede solo considerar los costos propios al evaluar las alternativas de solución de dudas y de conflictos, esto es, los costos de la FNE en un acuerdo extrajudicial pre-procesal o pre-procedimental versus los costos de la FNE en una consulta o en un litigio, sino que en estos últimos casos debe también ponderar los costos globales del sistema antimonopólico, esto es, los que respectivamente asumen el TDLC y la Excma Corte Suprema con motivo de una consulta o un litigio referido a la libre competencia. Los recursos del sistema antimonopólico son escasos y la FNE tiene el deber de emplearlos con miras a la mayor eficiencia combinando el mínimo insumo de costos posible con la mayor velocidad en la solución de dudas o conflictos vinculados a la libre competencia.

Así, la prelación basada en el principio de la eficiencia se inicia con opciones autocompositivas, continúa con variantes mixtas, esto es, en parte autocompositivas y en parte heterocompositivas, y acaba con alternativas puramente heterocompositivas. A nuestro juicio esta prelación podría esbozarse como sigue:

1. Intentar acuerdos extrajudiciales en estadios pre-procesales o pre-procedimentales a través de los cuales se previenen consultas y demandas antimonopólicas. Ésta es precisamente la novedad que introduce la Ley 20.361 a través de la incorporación de una letra ñ) al artículo 39 del Decreto Ley 211.

2. Intentar acuerdos extrajudiciales o judiciales en estadios procesales o procedimentales ventilados ante el TDLC o ante la Excma Corte Suprema. Así, por ejemplo, la conciliación está concebida como un trámite obligatorio según el cual el TDLC llama a las partes a buscar una conciliación antimonopólica una vez agotada la fase de discusión; se trata de un acuerdo judicial en un estadio procesal.

3. Conducir los procedimientos ventilados ante el TDLC hasta su término, esto es, hasta la dictación de una resolución o de una sentencia y agotar los recursos procesales, según corresponda. Ésta es la tercera alternativa porque, sin lugar a dudas, es la más onerosa para los intervinientes o las partes toda vez que se trata de una fórmula puramente heterocompositiva.

A medida que un litigio progresa, los costos incrementales de litigación versus los acuerdos de las partes en controversia decaen y se torna menos probable alcanzar autocomposiciones del conflicto antimonopólico ${ }^{43}$. Lo mismo cabe seńalar respecto de un procedimiento consultivo en el orden antimonopólico.

43 Richard Posner, "Economic Analysis of Law", pg. 560, Little, Brown and Company, Boston, 1992. 
